\title{
The Communitarian Turn: Myth or Reality?
}

\author{
RUTH CHADWICK
}

Browne is contending that we should no longer think of higher education as the provision of a public good, articulated through educational judgment and largely financed by public funds (in recent years supplemented by a relatively small fee element). Instead, we should think of it as a lightly regulated market in which consumer demand, in the form of student choice, is sovereign in determining what is offered by service providers (i.e. universities). The single most radical recommendation in the report, by quite a long way, is the almost complete withdrawal of the present annual block grant that government makes to universities to underwrite their teaching, currently around $£ 3.9$ billion. This is more than simply a "cut," even a draconian one: it signals a redefinition of higher education and the retreat of the state from financial responsibility for it.

Stefan Collini, “Browne's Gamble"1

This quotation from the London Review of Books is an example of a turna different way of looking at things that involves a redefinition of the kind of thing higher education is and how it should be provided. It is a turn away from a public good perspective-the opposite, it might be said, of the kind of turn addressed in this article.

The term "communitarian turn" itself needs some clarification. I am referring to a perceived-or argued for-shift in bioethics over the last decade or so, involving greater emphasis on principles of solidarity, equity, and public good, as opposed to the predominance of autonomy-based argument. It is beyond the scope of my discussion to deal in any detail with broader shifts that may or may not have occurred in the sociopolitical or indeed broader philosophical contexts, although they may be relevant. It may be appropriate, however, to mention other discussions on related themes: the debate about Aristotelianism versus Enlightenment thinking following the publication of Alasdair MacIntyre's After Virtue; ${ }^{2}$ the political debate in countries such as the United Kingdom in the 1990s about the importance of community, following the Thatcher era's dismissal of the notion of society in favor of individuals and families; the debate about "European" versus "American" values, with the purported-though controversial-greater emphasis on solidarity in the European context. I am not addressing any of these debates directly, although they may have a bearing on the topic of my discussion.

The domain of bioethics to which the purported communitarian turn relates also needs clarification. Bioethics includes both an academic literature and a public policy orientation. In relation to both, it is pertinent to be very clear 
about the distinction between description of a trend and arguing for a trend. There are issues to address about what would count as evidence of a shift. In the academic literature, one might look at the proportion of papers that might be classified as being written from a communitarian perspective, for example. Systematic research on this topic perhaps remains to be carried out. Policy pronouncements are another potential source of evidence of a communitarian turn. I want to suggest that it is policy considerations that have driven the turn, in light of real questions about what is possible and appropriate in a variety of circumstances, although it is true that in academic bioethics there also have been claims about a change of emphasis, for example, toward public health issues.

In the policy literature a possible example of evidence of a turn is to be found in the following quotations from the World Health Organization, speaking of genetic databases: "[T]he justification for a database is more likely to be grounded in communal value, and less on individual gain. . . . [I]t leads to the question whether the individual can remain of paramount importance in this context." 3 And: "[T] collective good may require a reconsideration of the respective claims so as to achieve an appropriate balance between individual and collective interests, including those of ethnic minorities, from a multi-cultural perspective." ${ }^{4}$ These quotations taken together arguably constitute a very strong statement of a turnthe language of reconsideration of the balance between individual and collective interests. The fact that they are arguing for a turn may in itself be partly evidence of a turn in progress. These quotations are also significant for another reason, in that they point to the context in which the arguments for a turn have been most prominent: that of developments in genetics and genomics.

Of course, to say that this trend is prominent in genomics, in particular, immediately invokes the specter of genetic exceptionalism. This is another debate in which I do not want to engage to any great extent, but although there may be features of the genetic and genomic context that do demand a different approach from other areas of biomedicine, that in itself does not suggest genetic exceptionalism unless it is claimed that it is only in this context that such approaches are appropriate. Some may make that claim but it is not one that I shall be making here. It may be possible, nevertheless, to suggest that there may be a difference between genetic and genomic exceptionalism. The debates about genetic exceptionalism focused on the claims that the special features of genetics include the facts that genetic information is shared between families, that it is predictive, and that it is independent of time. Against this, it has been argued that these characteristics also apply to other types of health information, at least to some degree. In addition, it is true only of genetic information contained in the nuclear genome and not of that in the mitochondrial genome, at least, not in the same way. It is in the period after the completion of the Human Genome Project, however, in the genomic or, some would say, postgenomic era that the debate about the communitarian turn has really taken off. Why is this? There are several possible reasons.

In the preceding quotations the $\mathrm{WHO}$ was talking about the development of biobanks, or genomic research databases. The terminology itself has been a matter of some discussion, but I will continue to use the word "biobank." And it is indeed the case that it is in this context that the call for, or identification of, a communitarian turn has been especially worthy of remark, as in the article by myself and Kåre Berg 


\section{Ruth Chadwick}

in 2001. ${ }^{5}$ In this article we were clearly calling for a greater emphasis on principles of solidarity and equity. The argument was, first, that it is not possible to rely on individual informed consent to do all the ethical work in this context, and, second, that there were ethical considerations relating to participation in research and sharing of the benefits that required alternative frameworks.

Whereas the 2001 article was clearly arguing for a turn, a 2005 article with Bartha Knoppers ${ }^{6}$ claimed to identify a shift. In 1994, in a piece in Science, ${ }^{7}$ we had identified the principles that were then, as we saw it, informing genetic research, and a decade later we claimed that there were "emerging trends" in ethics, speaking of a turn toward equity, mutuality, reciprocity, and solidarity. Our observations were influenced by work we were doing as members of the Ethics Committee of the Human Genome Organisation (HUGO), in whose statements it is also possible to see arguments for, and thus possibly evidence of, a shift.

For example, let us consider the following, in the 2007 statement dealing with pharmacogenomics. The committee is very open in saying that certain ethical principles should have greater prominence: "Past HUGO Ethics Committee Statements have reflected a commitment to the view that the highest ethical priority in implementing genomic knowledge is that of saving lives and reducing suffering, but the Committee considers it urgent that the ethical principles of solidarity and equity be given increased attention. ${ }^{\prime 8}$ In that statement the committee also proceeded to spell out their interpretation of the principles of solidarity and equity:

- Solidarity: Because of shared vulnerabilities, people have common interests and moral responsibilities to each other. Willingness to share information and to participate in research is a praiseworthy contribution to society.

- Equity: To reduce health inequalities between different populations, and to work towards equal access to care is an important prerequisite for implementing genomic knowledge for the benefit of society. ${ }^{9}$

And just in case there should be any doubt, the practical implications of the application of these principles were also spelled out:

4.1. All stakeholders in PGx research should exercise their ethical responsibilities in a spirit of equity and solidarity.

4.2. Voluntary participation of members of a community in PGx research provides an opportunity to actualise the principle of solidarity. Researchers have an obligation to engage the community while maintaining the highest standard of research conduct to earn the trust of the community.

4.3. The participation of all stakeholders, including the wider community, in such research requires public and professional dialogue and education in the science and ethics of PGx. ${ }^{10}$

So how should this be regarded? It might appear that the committee has chosen a particular way of framing the issues: that they could just as easily have taken a different approach. It is important to be clear, therefore, about what is going on in these debates. For if the ethical principles to apply are just a matter of choice, then from one point of view it might appear that what is happening is that ethical protections are in danger of being watered down for the sake of scientific convenience. Indeed it is part of the sad lot of bioethicists that they are accused 
on the one hand of wanting to stop science and on the other of not stopping anything. That is one reason why it is important to look at where the calls for a shift of ethical emphasis are coming from. Are they really being made from an impartial point of view?

Let us play devil's advocate and suppose for a moment that maybe the argument is that individual interests have to give way to the facilitation of scientific research because the possible good (that can be produced by scientific progress) outweighs the potential harm. The relationship between ethical protection and the facilitation of good science remains sensitive. On the one hand, a backlash has been observable among those who see ethics as burdensome bureaucracy, stopping science from achieving public good. On the other hand, however, there might be a genuine attempt to balance interests, not necessarily in a crass way that simply argues that the good of science outweighs all other interests but in a way that holds that in biobank research the risks to individuals are minor, as compared with, for example, clinical trials of a new pharmaceutical, and the benefits to the community possibly great.

However it should not be overlooked that, historically, some have argued that science is ethical in itself, even to the extent that the interests are incommensurable: "[T] he experiment itself is so elegant as to be equivalent to being ethical."11 And, "A human life is nothing compared with a new fact. ... [T] is the advancement of human knowledge at any sacrifice of human life."12 It might be objected that these types of argument, which are less frequently heard nowadays, are talking about the value of knowledge rather than the public good benefits that can come out of biobank research. However, it is not always easy to make a distinction here. It has been argued that knowledge is itself the archetypal public good, and that other public good arguments are derivable from that (cf. HUGO Statement on Genomic Databases). ${ }^{13}$

The more common type of argument, however, is in terms of health benefits outweighing what is considered to be the potential minor inconvenience to people, as participants in biobank research, insofar as they can be protected by appropriate governance arrangements. The general point is that there are more important (communal) interests at stake.

\section{Value Impact}

There are other possible explanations of the calls for a turn, however, apart from a watering down of ethics or a genuine attempt at a balancing exercise. Another possible explanation is that the individual-centered principles simply do not work in this context (as suggested in the 2001 article mentioned previously). ${ }^{14}$ This is a logical point, rather than a balancing point, and has been discussed most obviously in the debates about the applicability of different forms of consent in the biobank context. In that case ethical principles are not simply a matter of choice.

In the early days of these debates, it was noticed that if samples are being stored for long periods for future research, then even the researchers cannot foresee the range of potential uses to which the samples could be put. Hence those researchers were not sufficiently informed to give the opportunity for a fully informed consent (setting aside worries about informed consent in other contexts). This simple fact has led to discussions about broad versus narrow consent, about secondary use and recontacting, and now about open consent. ${ }^{15}$ 


\section{Ruth Chadwick}

The logic is simple and relies on the point that ought implies can. If we cannot apply certain principles in a new context, it makes no sense to say that we ought to. Informed consent as it is understood in a randomized controlled clinical trial cannot work in the same way in biobank research: although the protection of informed consent is still important, the underlying interests that are to be protected do not arise in the same way in biobank research as in other kinds of biomedical research, and this accounts for the new kinds of issues that are arising.

This type of change in ethics I have described is termed "value impact," to refer to the ways in which developments in science and technology, in particular, affect the ways in which we look at the world from an ethical point of view. The term is not intended to describe a linear process or to imply specific claims of cause and effect. It is intended to denote the ways in which ethics inevitably responds to scientific developments. We know that the boundaries of our very concepts change along with science and technology: artificial reproductive technologies, for example, have changed our understanding of the concepts of "mother" and "embryo." The events of the late 1970s and early 1980s gave birth to the concept of "pre-embryo" in addition to children born of IVF. It would be rash to assume that our ethical concepts are somehow immune to this.

What needs to be made clear is what this phenomenon is, and what it is not. It is not, of course, a new point that our understanding of ethical concepts is a subject to ongoing discussion-there are different, competing conceptions of autonomy, for example, and justice-which is what has led to the latter being described as an "essentially contested concept." But what I am describing is something different and apart from the ongoing philosophical analysis of concepts that is characteristic of the field. It is conceptual and theoretical development in response to science that is at issue. It also needs to be made clear that, despite talk of "new" ethical principles ${ }^{16}$ and despite the fact that it is clear that ethical theories (such as Kant's ethics and utilitarianism) and principles do emerge in specific historical circumstances, what is at stake here need be nothing so grand as completely new. The communitarian turn, whether identified or argued for, is toward existing ways of thinking about ethics that draw on preexisting traditions of thought, but that may have had less emphasis in bioethics to date.

It is no accident that a term that has been prominent in these debates about the communitarian turn is "framework." What is an ethical framework? We might regard it as a set of principles to be applied to the issues before us, but the explanation of applied ethics in terms of the application of a principle or set of principles is fraught with problems. ${ }^{17}$ I therefore suggest we should take a clue from the "frame" in "framework." An ethical framework then becomes the set of assumptions and principles with which we determine, for example, what is relevant from a moral point of view, who or what counts as an object of moral concern. But there are always issues about what might be left outside of the frame. This point has emerged quite strongly in the debates about the empirical turn in bioethics and in the social science criticisms of the field. For example, in the 1990s, in the debates about GM foods, particularly in the United Kingdom, the dominant framework used in policy, at least, was that of risk assessment. However, empirical research showed that among different sections of the public, risk assessment was not reassuring, because that was not the main issue: not only 
were there "unknown unknowns" to be concerned about, but there were also deep intuitions about tampering with nature that were not allowed inside the frame because they were regarded as irrational. Since then, also, there have been, from time to time, discussions about the "yuck factor" and about whether it should be allowed inside the frame.

The fact that it is necessary to pay attention to how issues are framed has been recognized by Anne Donchin and Deborah Denis, writing in Bioethics that one of the key challenges facing the field is "how to shift the locus of bioethical dialogue to bring to the foreground implicit assumptions that frame central issues and determine whose voices are to be heard." ${ }^{18}$ The point is that we cannot avoid having some frame: another metaphor might be in terms of the lens through which we see things, which can be adjusted to zoom or wide angle, affecting what we are aware of. It is important constantly to be aware of what might be left outside, as well as what is within.

\title{
What Is Communitarian about the Communitarian Turn?
}

Surely, it may be asked, to speak in this way, and indeed to talk of a communitarian turn, requires some understanding of the concept of community itself? So, what is it? The HUGO Ethics Committee examined this in the earlier Statement on Benefit-Sharing (2000), in which it distinguished between communities of origin and communities of circumstance:

\begin{abstract}
Both types of communities can be defined across several dimensions, including geography, race/ethnicity, and religion or disease state. For example, a small town may be a community of origin if most inhabitants were born there, or a community of circumstance if most are newcomers. Persons with the same disease could form a community of origin if there is a family history, as may be the case for monogenic disorders (single gene), or a community of circumstance, which is usually the case for common multifactorial diseases. People with common multifactorial diseases, such as heart disease, hypertension, cancer, or diabetes may not regard themselves as communities. ${ }^{19}$
\end{abstract}

An analogous distinction can be made between different senses of solidaritybecause there is an issue concerning to whom one is supposed to show solidarity. A distinction has been made between communal solidarity and constitutive solidarity: "Communal solidarity is that practised by a group of people having a common interest, whereas constitutive solidarity is that practised by people having an interest in common. ${ }^{\prime 20}$ We have common interests by virtue of being human beings, but we can have interests in common through circumstances that lead us to form groups to protect those interests.

This is already suggestive of the fact that the ethical frameworks we use to identify and protect those interests are not a matter of choice alone. We have to consider the extent to which there are logical constraints on the frameworks we use (just as Bernard Williams argued that it is a matter of logic that healthcare should be distributed on the basis of need). ${ }^{21}$

Again, I do not propose to be all-embracing in this discussion. To ask whether there are any logical constraints on the ethical frameworks we use is at one level to reopen all the debates about the language and logic of morals, whether there 


\section{Ruth Chadwick}

are any categorical imperatives, or whether it is just a system of hypothetical imperatives, and so on. My aim is much narrower than that and brings me back to the debates about genomics.

I have already claimed that as science and technology develop, there are consequences for the concepts we use, what I call value impact. Two examples are predominant in the literature-that of informed consent has been mentioned. The second is that of privacy. If we cannot guarantee individual privacy any more, then why go on pretending? This is the basic argument in the paper by Lunshof and colleagues "From Genetic Privacy to Open Consent." ${ }^{22}$ The real threat to privacy is not the intentional inroads into it by governments and corporations, but the side effects of new technologies that make it actually impossible to protect it. There may be those who would argue that although reidentification of individuals through their DNA is always a theoretical possibility, it is a remote one and so is not to be taken too seriously, but that is not the point.

In discussing privacy, Helen Nissenbaum ${ }^{23}$ has argued that the norms of information flow that are appropriate in one context may not be so in another. For example, the information I am and should be willing to reveal to my friend is different from that which I am willing to reveal to my doctor. This raises a point about how a context is defined and whether the norms applicable within a context can change. Unless they are somehow internal to the context, they can. In other words, they may be contingently rather than logically connected with a context.

If this is the case, then even within the context of biomedical research, the applicable norms can be subject to change. Alternatively, if there are norms that are connected with the internal logic of a context, then this might be the case even within different subcontexts of particular areas of life-for example, different types of research within biomedicine. This seems to be a central issue to be discussed-is there something about the logic of genomics that makes a communitarian turn appropriate?

\section{Broadening the Discussion}

Having attempted to show that this may indeed be appropriate, and why developments in genetics and genomics have problematized some traditional ways of looking at things, such as particular conceptions of informed consent and privacy protection, it is time to consider broadening the discussion again. Although we have discussed the issue of internal logic in particular contexts, there is a question about whether these different ways of looking at things may also be appropriate in other contexts. Privacy, for example, is also under threat in the surveillance context, as well as on the Internet from social networking, from Google Maps Street View, and so on. It would be premature to assume that these contexts are so different that a review of ethical frameworks is not appropriate there as well. We have always to keep an open mind as to what may be outside the frame.

\section{Conclusion}

So (1) has there been a communitarian turn? And (2) should there be? These questions are still open to (1) the production of evidence and (2) debate. The main point I want to make is that, whatever the answers to those questions, we need 
(1) specific attention to framing and (2) attention to the internal logic of contexts. There may not be a one-size-fits-all approach. The idea of value impact shows us that scientific developments lead to new contexts for biomedical research, and that we may find that principles that have worked very well in specific contexts in the past are not simply transferable. We may need to "turn" to other traditions of thought, which may be more community based than the individualism that dominated bioethics in its first decades. And even within a context, it is important to be alive to the logic of the context and to what is only contingently connected. The rapid change brought about by social networking has demonstrated that the concept of friendship, as well as biomedical concepts, can be turned upside down, so we should not assume that turns such as the purported communitarian turn I have been discussing are only to be found in biomedicine.

\section{Notes}

1. Collini S. Browne's gamble. London Review of Books 2010;32(21):23-5.

2. MacIntyre A. After Virtue: A Study in Moral Theory. Notre Dame: University of Notre Dame Press; 1981.

3. World Health Organization. Genetic Databases: Assessing the Benefits and the Impact on Human and Patient Rights. Geneva: WHO; 2003, p. 7.

4. See note 3, World Health Organization 2003.

5. Chadwick R, Berg K. Solidarity and equity: New ethical frameworks for genetic databases. Nature Reviews Genetics 2001;2(4):318-21.

6. Knoppers BM, Chadwick R. Human genetic research: Emerging trends in ethics. Nature Reviews Genetics 2005;6:75-9.

7. Knoppers BM, Chadwick R. The Human Genome Project: Under an international ethical microscope. Science 1994;265:2035-6.

8. Human Genome Organisation (HUGO). Statement on Pharmacogenomics (PGx): Solidarity, Equity and Governance. Genomics, Society and Policy 2007;3:45.

9. See note 8 , HUGO 2007:45.

10. See note 8 , HUGO 2007:46.

11. Clarke CA. Problems raised by developments in genetics. In: Ebling FJ, ed. Biology and Ethics. London: Academic Press; 1969, at 96.

12. Vyvyan J. The Dark Face of Science. London: Michael Joseph; 1971, at 21.

13. Human Genome Organisation (HUGO) Ethics Committee. Statement on Human Genomic Databases. London: HUGO; 2000.

14. See note 5, Chadwick, Berg 2001

15. Lunshof J, Chadwick R, Vorhaus DB, Church GM. From genetic privacy to open consent. Nature Reviews Genetics 2008;9:406-11.

16. As in the 2001 article by myself and Kare Berg, for example.

17. Chadwick R. What is "applied" in applied ethics. Journal of Applied Ethics 2009;1:1-7.

18. Donchin A, Diniz D. Guest editors' note. Bioethics 2001;15(3):iii-v.

19. Human Genome Organisation (HUGO) Ethics Committee. Statement on Benefit-Sharing. London: HUGO; 2000, at 2.

20. See note 6, Knoppers, Chadwick 2005.

21. Williams B. The idea of equality. In: Laslett P, Runciman WG, eds. Philosophy, Politics and Society. 2nd series. Oxford: Blackwell; 1962.

22. See note 15, Lunshof et al. 2008.

23. Nissenbaum H. Privacy as contextual integrity. Washington Law Review 2004;79(1):119-58. 